\title{
A Numerical Investigation of Effects of Cutting Velocity and Feed Rate on Residual Stresses in Aluminum Alloy Al-6061
}

\author{
Sohail Akram, Syed Husain Imran Jaffery, Mushtaq Khan, Aamir Mubashar, and Liaqat Ali
}

\begin{abstract}
The aim of this research was to investigate the residual stresses in an aluminum alloy Al-6061 workpiece after machining. The sensitivity of residual stresses to cutting speed and feed rate was determined using finite element method. Tensile residual stresses at the surface of components are generally undesirable as they contribute to fatigue failure, quench cracking and stress-corrosion cracking. A two dimensional model of machining was developed using commercially available finite element software, Abaqus, to simulate orthogonal cutting of Al-6061 alloy. Numerical simulations of orthogonal cutting of the workpiece were carried out at various preselected combinations of feed rate and cutting speed. The simulation results showed that residual stresses were insensitive to changes in cutting speed, however, residual stresses were clearly affected by the change in feed rate.
\end{abstract}

Index Terms-Finite element method, machining, orthogonal cutting, residual stresses.

\section{INTRODUCTION}

Since the industrial revolution in last 100 years, modern economics largely depend upon the manufacturing technology. Despite highly sophisticated manufacturing technology, many tool designs and processes still depends upon the experience and intuition [1]. Aerospace alloys with unique metallurgical properties such as aluminum, titanium, nickel, stainless steel and other super alloys are being produced in order to produce high performance materials with much stronger strength and high corrosion, abrasion or heat resistance. In modern technologies such as aerospace, submarines and automotive industries etc., specific design improvements and pertinent machining techniques have to be developed accordingly. As new materials with high hardness, toughness and fatigue strength, heat and corrosion resistance are being developed, they are also posing much difficulty when it comes to the machining of these alloys. Therefore, these materials are traditionally considered to be hard-to-machine owing to their strong tendency to strain hardening, maintaining their high strength even at elevated

Manuscript received December 26, 2013; revised March 28, 2014 Sohail Akram is with the School of Mechanical \& Manufacturing Engineering (SMME), National University of Science and Technology (NUST), Islamabad, Pakistan (e-mail: sohailakram77@yahoo.com).

Syed Husain Imran Jaffery, Mushtaq Khan, and Liaqat Ali are with the Department of Design and Manufacturing, School of Mechanical \& Manufacturing Engineering (SMME), National University of Science and Technology (NUST), Islamabad, Pakistan (e-mail: \{Imran, mkhan, aamirmub\}@smme.nust.edu.pk).

Aamir Mubashar is with the Department of Mechanical Engineering, School of Mechanical \& Manufacturing Engineering (SMME), National University of Science and Technology (NUST), Islamabad, Pakistan. temperatures, often their lower thermal conductivity constrain the heat produced near tool tip causing problems due to extreme temperature rise.

Primary objective in machining operations is to develop low cost and high quality products. Optimization of machining parameters play a vital role in achieving these goals while involving the optimal selection of cutting conditions i.e. cutting speed, depth of cut, feed-rate and number of passes. All these parameters affect the resulting surface roughness, residual stresses, fatigue strength and microstructural characteristics.

The scope of this work is to investigate the effects of feed rate and cutting speed on residual stresses in an aluminum alloy Al-6061 workpiece after machining.

The research work includes:

1) Development of an orthogonal cutting numerical model using commercially available finite element code.

2) Usage of an advanced mathematical material model to include the nonlinear material behavior including plastic deformation and damage. The material model also includes a failure criterion.

3) Using the numerical model, study the effect of preselected combinations of feed rate and cutting speed on residual stresses in aluminum Al6061.

\section{LITERATURE REVIEW}

The current research in the field of machining is taking full advantage of the availability of compute clusters that provide high computing power and sophisticated numerical codes that can run on parallel systems. Effect of machining parameters such as cutting forces, temperatures, chip morphology, residual stresses and strains can be predicted for new and existing materials, prior to actual machining operation. Experimental approach, which is mostly based on experience and trial and error, is costly as well as time consuming and laborious. Numerical modelling on the other hand can spare resources thus reducing cost and can be used to optimize cutting parameters.

Numerical simulation of machining processes is a challenging task and presents many challenges. Machining operation involves the usage of non-linear material models that can predict plastic deformation and failure of material. Failure of material results in generation of new surfaces and contact between the tool and material changes with time. The variation of workpiece and tool properties, geometrical characteristics, machining conditions including cutting velocity, feed-rate and depth of cut, usage of cutting fluid or dry machining and the interaction of all the above in the same 
system increases the complexities of a numerical model [2].

Orthogonal machining using 2-D finite element model has been simulated by many researchers, considering variety of aspects. M Agmell et al. [3] performed a fully coupled thermo-mechanical 2-D analysis in Abaqus for orthogonal cutting using AISI 4140 steel. The influence of theoretical chip thickness on the shape of deformation zone was studied. The results showed that $2 \mathrm{D}$ finite element model was capable of representing the various deformation zones induced during cutting. J. L. Bacaria et al. [4] took into account dynamic effects, thermo-mechanical coupling, constitutive damage law and contact with friction to study unsteady-state process of chip formation using 2D and 3D FEM model for 42CD4 steel. The finite element model results showed that the formation of the chip resulting from the intrinsic behavior of the material was realistic. The influence of temperature and heat partition at the tool rake face, on the tool wear mechanism was analyzed by F. Akbar et al. [5] simulated orthogonal turning operation for AISI 4140 steel using tungsten based cemented carbide cutting tools and concluded that the prediction of machining process needs an accurate determination of heat partition between tool-chip interface. Large strain deformation response of Al 6061-T6 had been studied by D. R. Lesuer et al. [6] over a range of strain-rates from $10^{-4} \mathrm{~s}^{-1}$ to $10^{4} \mathrm{~s}^{-1}$ to critically calculate the strength and damage components of Johnson Cook (JC) material model. They proposed a new material model that addressed the shortcomings of the JC material model while considering the influence of void formation on yield and flow behavior. Hongtao Ding et al. [7] used plane-strain orthogonal cutting process for modelling of grain refinement in Al 6061-T6. The grain size in the mechanical chips of Al 6061 T6 were refined from an initial grain size of $75 \mu \mathrm{m}$ to about $160 \mu \mathrm{m}, 100 \mu \mathrm{m}$ and $80 \mathrm{~nm}$ under varying levels of applied shear strains ranging from 1.8 to 5.2 . This was imposed by changing tool rake angles ranging from $20^{\circ}$ to $-20^{\circ}$. A higher negative rake angle tool was selected to reduce the grain size in the chip by applying a large strain.

Albert J. Shih [8] applied orthogonal metal cutting of annealed low carbon steel to study the effects of rake angle on residual stresses. It was observed that the increase of co-efficient of friction had less impact on the cutting with larger rake angle. For zero or negative rake angle, it remained insensitive to change in cutting speed. Moreover, J.C. Outeiro et al. [9] presented the influence of cutting process parameters on machining performance and residual stresses induced by dry-turning of inconnel-718 and austenitic stainless steel AISI 316L with coated and uncoated carbide tools. It was reported that measured residual stresses in both materials were highly tensile at the machined surface while compressive stresses were found in the sub-surface below $10-25 \mu \mathrm{m}$. Moreover, machining with uncoated tool resulted in higher surface residual stresses compared to coated tool.

Establishing a relationship between the magnitude of residual stresses, after machining of a material, and cutting parameters may provide an opportunity for process improvement. This can be achieved by selection of cutting parameters to reduce or increase the residual stress magnitude observed after machining. This is especially applicable to high strength aerospace alloys such as Al-6061. Control of residual stress would help in improving the fatigue life, which is one of the critical failure factors in aerospace industry.

\section{FInITE ELEMENT MODELLING}

The commercially available finite element code Abaqus was used for numerical modelling and simulations. The details of the model development and numerical simulations techniques used in this research are discussed next.

A two dimensional finite element model was used to simulate the effects of residual stresses. Since, no change in material cross-section was assumed, the two dimensional model with plane strain formulation provides reliable results [3], [5], [10], [11]. The machining operation was also considered orthogonal, which represents the turning conditions adequately [3], [5], [10], [11]. During the machining process, the deformation of the workpiece occurs at a high rate resulting in a dynamic loading condition. This type of phenomenon is best captured by using explicit finite element codes and Abaqus/Explicit was used for the purpose. Residual stresses arising from the mechanical cutting action were only considered in this research.

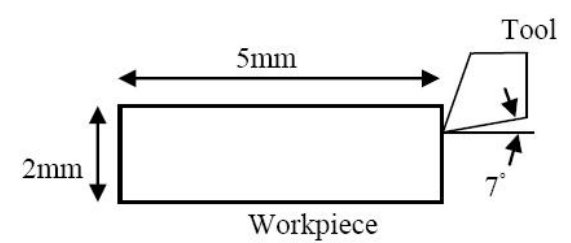

Fig. 1. Geometry of workpiece and tool position (not to scale).

The workpiece and tool geometry is shown in Fig. 1. The workpiece dimensions are $5 \times 2 \mathrm{~mm}$. The dimensions were chosen so that the workpiece is enough to obtain a consistent chip formation during the simulation and its height should be enough to capture the stresses resulting from surface machining. The tool geometry was selected based on the commercially available tools for machining of aluminum. The tool CCMW 09 T3 04 (ISO specification) has a nose radius of $0.4 \mathrm{~mm}$ and rake angle $0^{\circ}$ and clearance angle of $7^{\circ}$ [12]. The tool was initially positioned so that the uncut chip thickness is $0.2 \mathrm{~mm}$. The workpiece was fully constrained at the bottom surface to avoid rigid body motion. The tool motion was constrained in $\mathrm{Y}$ direction and was given a velocity in $\mathrm{X}$ direction.

Johnson-Cook (JC) material model was used for the Al-6061 work piece material. This model is suitable for problems where strain-rates vary over a large range $\left(10^{2}-10^{6}\right.$ $\mathrm{s}^{-1}$ ) [3], [5]. The JC model is capable of predicting the plastic deformation as well as damage and failure. The stress in plastic deformation regime is given by the following equation [3]-[5], [11], [13]-[15]:

$$
\begin{aligned}
\bar{\sigma}=\left(A+B \bar{\varepsilon}^{n}\right)[ & \left.1+C \ln \left(\frac{\dot{\bar{\varepsilon}}}{\dot{\overline{\varepsilon_{0}}}}\right)\right][1 \\
& \left.-\left(\frac{T-T_{\text {room }}}{T_{\text {melt }}-T_{\text {room }}}\right)^{m}\right]
\end{aligned}
$$

where $\bar{\sigma}$ is the equivalent stress, $\bar{\varepsilon}$ the equivalent plastic strain, $\dot{\bar{\varepsilon}}$ the plastic strain rate, $\dot{\bar{\varepsilon}}_{0}$ the reference strain rate $(1.0$ 
$\mathrm{s}^{-1}$ ), A is the initial yield stress, $\mathrm{B}$ is the hardening modulus, $n$ the work-hardening exponent, $\mathrm{C}$ the strain rate dependency coefficient, $m$ is the thermal softening coefficient, $T_{\text {room }}$ is the room temperature and $T_{\text {melt }}$ is the melting temperature. Values of Johnson-cook material model for Al-6061 are available in literature and are given in Table I.

TABLE I: JOHNSON COOK MATERIAL MODEL PARAMETERS FOR ALUMINUM ALLOY AL-6061 [6], [16]

\begin{tabular}{|l|l|}
\hline Material Property & Value \\
\hline Density & $27000 \mathrm{~kg} / \mathrm{m}^{3}$ \\
\hline Young's Modulus & $68.9 \mathrm{GPa}$ \\
\hline Poisson's ratio & 0.33 \\
\hline Initial yield stress, A & $324 \mathrm{MPa}$ \\
\hline Hardening modulus, B & $114 \mathrm{MPa}$ \\
\hline Strain hardening exponent, $\mathrm{n}$ & 0.42 \\
\hline Strain rate coefficient, C & 0.002 \\
\hline Reference strain rate & $1 \mathrm{sec}^{-1}$ \\
\hline
\end{tabular}

JC model damage and failure is based on a cumulative damage law given below [3], [4], [11], [13]-[15]:

$$
D=\sum\left(\frac{\Delta \bar{\varepsilon}}{\bar{\varepsilon}_{f}}\right)
$$

where, $\Delta \bar{\varepsilon}$ is the increment of the equivalent plastic strain. According to the Johnson-Cook damage model, the cumulative strain $\Delta \bar{\varepsilon}$ is updated at every analysis increment and $\bar{\varepsilon}_{f}$ is the equivalent strain at failure and is expressed as the following equation [3]-[5], [11], [15]:

$$
\begin{gathered}
\bar{\varepsilon}_{f}=\left[D_{1}+D_{2} \exp \left(D_{3} \frac{P}{\bar{\sigma}}\right)\right]\left[1+D_{4} \ln \left(\frac{\dot{\bar{\varepsilon}}}{\dot{\overline{\varepsilon_{0}}}}\right)\right] \times \\
{\left[1+D_{5}\left(\frac{T-T_{\text {room }}}{T_{\text {melt }}-T_{\text {room }}}\right)\right]}
\end{gathered}
$$

where $\overline{\varepsilon_{f}}$ depends on the equivalent plastic strain rate $\dot{\bar{\varepsilon}}$, the ratio $\frac{\dot{\bar{\varepsilon}}}{\bar{\varepsilon}_{0}}$, the ratio of hydrostatic pressure to equivalent stress $\overline{\bar{\sigma}}$, and the temperature. The values of damage constants $\left(D_{i}\right.$, where $\left.1 \leq i \leq 5\right)$ are given in literature and are given in Table II.

TABLE II: J-C MATERIAL MODEL DAMAGE PARAMETERS [6], [16]

\begin{tabular}{|l|l|}
\hline Initial failure strain, D1 & -0.77 \\
\hline Exponential factor, D2 & 1.45 \\
\hline Triaxiality factor, D3 & -0.47 \\
\hline Strain rate factor, D4 & 0.0 \\
\hline Temperature factor, D5 & 0.0 \\
\hline
\end{tabular}

By using a material model which can predict material failure, the finite element model does not a predefined chip thickness. The workpiece material is removed by the shearing action of the tool.

The tool was considered rigid in this study as the residual stresses were the focus of the research. The workpiece region where material failure is expected because of the cutting operation was meshed with a fine mesh and the rest of the workpiece was meshed with a coarse mesh. This helps in reducing the overall number of elements and thus computational cost. Plane-strain, quadrilateral elements with reduced integration, CPE4R elements were used to mesh the workpiece. Severe distortion of mesh occurs during the machining simulation. Arbitrary Lagrangian-Eulerian (ALE) formulation was used to reduce the mesh distortion during the simulation. ALE Adaptive mesh domain was assigned to the workpiece and frequency for the remeshing was taken as 100 In an adaptive meshing increment a new, smoother mesh is created by sweeping iteratively over the adaptive mesh domain. During each mesh sweep, nodes in the domain are relocated based on the current positions of neighboring nodes and elements to reduce element distortion.

Surface based contact was used to define the tool workpiece interaction. The general contact algorithm was not applicable as internal surfaces are generated due to chip formation during simulation and contact between newly generated surfaces and tool is required for continuous chip development. The tangential behavior of the contact was based on penalty-method. Columb friction model was used with a friction coefficient of 0.5 [3].

\section{RESUlTS AND DISCUSSION}

The depth of cut was fixed in all these simulations while cutting velocities and feed-rates were varied. Combinations of cutting velocity and feed-rate used in various simulations are given in Table III.

TABLE III: COMBINATIONS OF CUTTING PARAMETERS USED DURING SimULATIONS

\begin{tabular}{|c|c|c|}
\hline $\begin{array}{c}\text { Simulation } \\
\text { No }\end{array}$ & $\begin{array}{c}\text { Cutting speed } \\
\mathrm{m} / \mathrm{min}\end{array}$ & $\begin{array}{c}\text { Feed-rate } \\
\mathrm{mm} / \mathrm{rev}\end{array}$ \\
\hline 1 & 250 & 0.2 \\
\hline 2 & 500 & 0.1 \\
\hline 3 & 500 & 0.3 \\
\hline 4 & 750 & 0.3 \\
\hline 5 & 250 & 0.3 \\
\hline 6 & 750 & 0.2 \\
\hline 7 & 500 & 0.2 \\
\hline 8 & 250 & 0.1 \\
\hline 9 & 750 & 0.1 \\
\hline
\end{tabular}

Simulation results show the production of serrated chips for all combinations of cutting speed and feed rate. The generated chip for one combination of cutting speed and feed is shown in Fig. 2 and is representative of the chip observed in all simulations. The predicted equivalent plastic strain in the workpiece after steady state chip formation is shown in Fig. 3. Highest plastic strain was predicted in the shear zone along the tool chip interface.

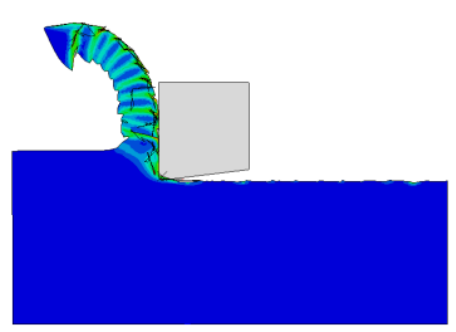

Fig. 2. The generated chip at $f=0.3 \mathrm{~mm} / \mathrm{rev}$ and cutting speed $=500 \mathrm{~m} / \mathrm{min}$.

Plastic strain was also observed below the machined 
surface, however, the layer of plastic strain under machined surface was of very small thickness. The primary and secondary shear zones can be more clearly seen by vonMises stress distribution in the workpiece as shown in Fig. 4.

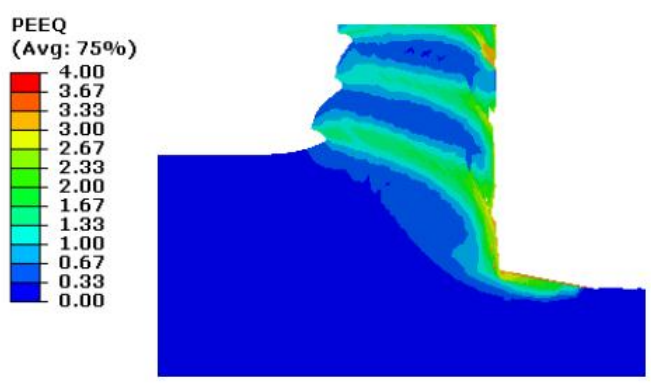

Fig. 3. Equivalent plastic strain in workpiece $(f=0.3 \mathrm{~mm} / \mathrm{rev}$ and cutting speed $=500 \mathrm{~m} / \mathrm{min}$ ).

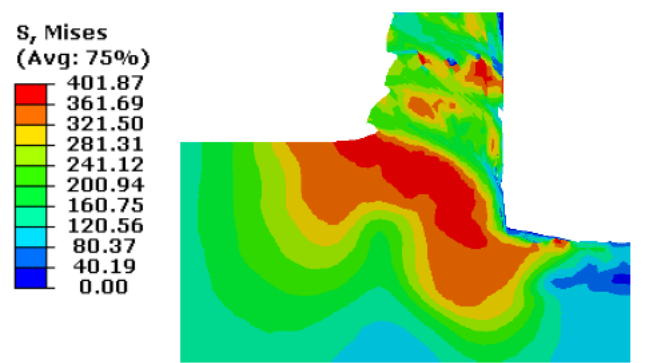

Fig. 4. vonMises stress in workpiece $(f=0.3 \mathrm{~mm} / \mathrm{rev}$ and cutting speed $=500$ $\mathrm{m} / \mathrm{min})$.

The predicted residual stresses in the workpiece after machining were measured for all the combinations of cutting velocity and feed rates. Fig. 5 shows plot of below surface residual stresses for $f=0.1$ and three different cutting velocities.

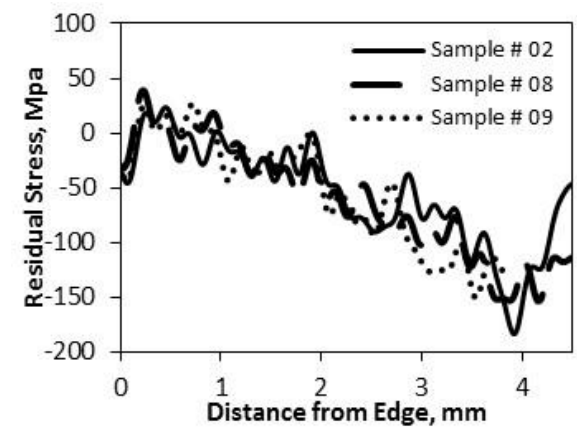

Fig. 5. Residual stresses in workpiece surface after machining for $f=0.1$ $\mathrm{mm} / \mathrm{rev}$. Cutting velocities: Sample $02=500 \mathrm{~m} / \mathrm{min}$, Sample 08=250 m/min, and Sample 09=750 $\mathrm{m} / \mathrm{min}$.

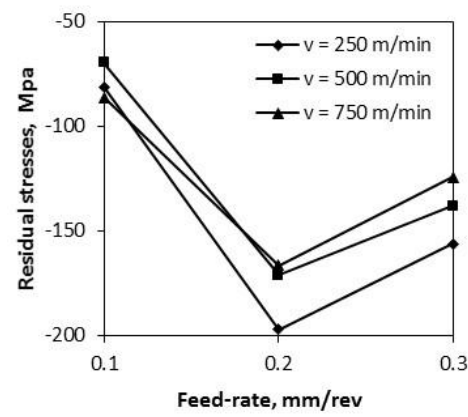

Fig. 6. Effect of feed rate and cutting velocities on residual stresses.

The zero in on the $\mathrm{x}$-axis represents the starting point of the tool and the distance along the edge is taken in the direction of cutting velocity. It can be seen that the residual stresses start to become compressive as soon as the tool starts to travel and chip starts to produce.

The compressive residual stresses start to increase when the feed-rate is changed from $0.1 \mathrm{~mm} / \mathrm{rev}$ to 0.2 reaching its maximum value and then decreases as the feed-rate is increased to $0.3 \mathrm{~mm} / \mathrm{rev}$. This can be observed in Fig. 6 .

It has been reported for Al6061-T651 [17] that cutting force decreases when cutting velocity is increased from 30 to $210 \mathrm{~m} / \mathrm{min}$ and the change in cutting force becomes minimal when cutting speed is further increased to $300 \mathrm{~m} / \mathrm{min}$. Thus the insensitivity of the residual stresses in present study may be related to the cutting force, which may not be decreasing significantly with increasing cutting velocity.

\section{CONCLUSIONS}

This study shows that:

1) Finite element modelling may be used to predict residual stresses after machining of components.

2) Reasonable chip formation may be achieved by using a material model with plasticity, damage and failure as well as having friction models.

3) Under the selected range of cutting velocities and feed-rates, the residual stresses at and below surface of workpiece are compressive.

4) Residual stresses were sensitive to feed-rate changes in the selected range, however, a clear trend of increase or decrease in residual stress with feed-rate change would require further investigation.

5) Residual stresses remained unchanged with the changing cutting velocities. This can be attributed to the minimal effect of cutting velocity on cutting force in the selected range.

\section{ACKNOWLEDGMENT}

The authors would like to thank Higher Education Commission, Pakistan for funding under the indigenous scholarship program at National University of Science and Technology (NUST), Islamabad, Pakistan.

\section{REFERENCES}

[1] H. Bil, "Simulation of orthogonal metal cutting by finite element analysis," Master thesis, The Middle East Technical University, August 2003.

[2] A. P. Markopoulos, "Cutting mechanics and analytical modeling," Finite Element Method in Machining Processes, Springer, 2013, pp. 11-27.

[3] M. Agmell, A. Ahadi, and J. E. Stahl, "A fully coupled thermomechanical two-dimensional simulation model for orthogonal cutting: Formulation and simulation," in Proc. the Institution of Mechanical Engineers, 2011, vol. 225, no. 10, pp. 1735-1745.

[4] J. L. Bacaria, O. Pantalé, R. Rakotomalala, and S. Capéraa, "2D and 3D numerical models of metal cutting with damage effects," Computer Methods in Applied Mechanics and Engineering, vol. 193, September 2000.

[5] F. Akbar, P. T. Mativenga, and M. A. Sheikh, "An experimental and coupled thermo-mechanical finite element study of heat partition effects in machining," The International Journal of Advanced Manufacturing Technology, vol. 46, issue 5-8, pp. 491-507, 2009.

[6] D. R. Lesuer, G. J. Kay, and M. M. LeBlanc, "Modeling large-strain, high-rate deformation in metals," presented at the third Biennial Tri-Laboratory Engineering Conference on Modeling and Simulation, Pleasanton, CA, July 20, 2001 
[7] H. Ding, N. Shen, and Y. C. Shin, "Modeling of grain refinement in aluminum and copper subjected to cutting," Computational Materials Science, vol. 50, issue 10, pp. 3016-3025, 2011.

[8] A. J. Shih, "Finite element analysis of the rake angle effects in orthogonal metal cutting," Int. J. Mech. Sci., vol. 38, issue 1, pp. 1-17, 1996.

[9] J. C. Outeiro et al., "Analysis of residual stresses induced by dry turning of difficult-to-machine materials," CIRP Annals Manufacturing Technology, vol. 57, issue 1, pp. 77-80, 2008.

[10] S. L. Soo, D. K. Aspinwall, and R. C. Dewes, "3D FE modelling of the cutting of Inconel 718," Journal of Materials Processing Technology, vol. 150, issue 1-2, pp. 116-123, 2004.

[11] M. Agmell, A. Ahadi, and J. E. Ståhl, “A numerical and experimental investigation of the deformation zones and the corresponding cutting forces in orthogonal cutting," Advanced Materials Research, vol. 223, pp. 152-161, 2011

[12] Sandvik Coromant Turning Tool Catalogue, AB Sandvik Coromant, SE-811 81 Sandviken Sweden, 2011.

[13] P. J. Arrazola and T. Ozel, "Numerical modelling of 3D hard turning using arbitrary Lagrangian Eulerian finite element method," Int. J. Machining and Machinability of Materials, vol. 3, no. 3, 2008

[14] M. H. Miguélez, M.-S. Ana, and J. L. Cantero, "An efficient implementation of boundary conditions in an ALE model for orthogonal cutting," Journal of Theoretical and Applied Mechanics, vol. 47, no. 3, pp. 599-616, 2009.

[15] E.-G. Ng and D. K. Aspinwall, "Modelling of hard part machining," Journal of Materials Processing Technology, vol. 127, pp. 222-229, 2002.

[16] L. E. Schwer, "Aluminum plate perforation: A comparative case study using Lagrange with erosion, multi-material ALE, and smooth particle hydrodynamics," presented at 7th European LS-DYNA Conference, 2009.

[17] ASM Handbook - Machining, 9th ed., American Society for Metals, 1989, p. 765

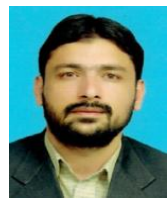

Sohail Akram was born at Tarbela, district Haripur on November 16, 1977. His early education including SSC and HSC (Pre-Eng.) was from Cadet College Kohat in 1994 and 1996 respectively and he received his BSc in mechanical engineering from University of Engineering \& Technology, Peshawar (Pakistan) in 2001-2002.

He completed his MS in design and manufacturing engineering in August
2013. He is working as a senior engineer at Heavy Mechanical Complex-3, Taxila since 2002

$\mathrm{He}$ is mainly involved in the design of mechanical equipment including heat-exchangers, storage tanks and equipment support structures.

Mr. Akram had been awarded merit scholarship in SSC board examinations and has also been nominated for HEC indigenous scholarship in 2011 and currently is in his PhD phase at the department of Design and Manufacturing Engineering, SMME (NUST) Pakistan.

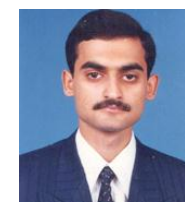

Syed Hussain Imran Jaffery has done his $\mathrm{PhD}$ (Manufacturing) from University of Manchester, UK. His area of specialization is industrial engineering and digital manufacturing. He is currently an assistant professor at Department of Design and Manufacturing SMME, NUST.

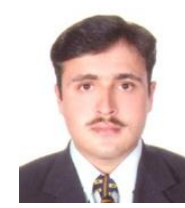

Mushtaq Khan is an assistant professor at the Department of Design and Manufacturing Engineering SMME, NUST. $\mathrm{He}$ has done his $\mathrm{PhD}$ from Loughborough University UK and his area of specialization is rapid prototyping/laser manufacturing.

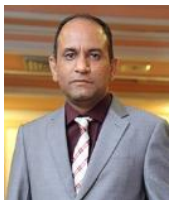

Aamir Mubashar is an assistant professor at National University of Science and Technology (NUST), Islamabad, Pakistan. He has done his $\mathrm{PhD}$ in mechanical engineering from Loughborough University, Loughborough, UK. His areas of interest are adhesive joints, composites, computational biomechanics and multiphysics modelling.

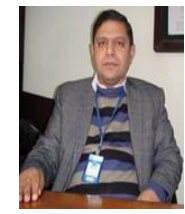

Liaqat Ali is currently the head of the Department in School of Mechanical and Manufacturing Engineering, NUST. He has done his $\mathrm{PhD}$ in manufacturing engineering from Loughborough University, UK. His area of specialization is advance manufacturing technology. 